\title{
CARACTERIZAÇÃO DE ORGANOSSOLOS EM AMBIENTES DE VÁRZEA DO NORDESTE DO BRASIL ${ }^{(1)}$
}

\author{
Rafael Cipriano-Silva ${ }^{(2)}$, Gustavo Souza Valladares ${ }^{(3)}$, Marcos Gervasio Pereira ${ }^{(4)}$ \& Lúcia \\ Helena Cunha dos Anjos ${ }^{(4)}$
}

\begin{abstract}
RESUMO
Os Organossolos são geralmente associados às regiões Sudeste e Sul do Brasil, e são poucos os estudos sobre a ocorrência e os efeitos do uso e manejo agrícola desses solos na região Nordeste. Os objetivos deste trabalho foram caracterizar física, química e morfologicamente seis perfis de Organossolos de várzeas dos Estados do Ceará, Rio Grande do Norte e da Paraíba e correlacionar seus atributos ao ambiente de formação, além de quantificar seus estoques de carbono e suas capacidades de armazenamento de água. Foram utilizados os métodos recomendados no Sistema Brasileiro de Classificação de Solos (SiBCS) para caracterizar química e fisicamente o solo, bem como a umidade e o volume residual dele. $\mathrm{O}$ aumento dos valores da Ds nos horizontes foi em decorrência da maior decomposição das fibras esfregadas (FE) e da redução dos teores de matéria orgânica. $O$ volume residual apresentou correlações positiva e significativa a 5 \% com o valor de resíduo mínimo $(r=0,64)$ e $D s(r=0,74)$ e negativa com a porcentagem de FE $(r=-0,75)$, podendo ser usado para avaliar a subsidência desses solos. As propriedades químicas foram influenciadas pelo material orgânico e pelos sedimentos fluviomarinhos. A variação da drenagem influenciada pela posição no relevo e pelo uso agrícola dos solos conduziu a classes de diferentes graus de decomposição da matéria orgânica e com isto às classes dos Organossolos Fíbrico, Hêmico e Sáprico. Um dos perfis CE1, com maior influência de sedimentos marinhos, foi classificado como Organossolo Tiomórfico com caráter solódico.
\end{abstract}

Termos de indexação: matéria orgânica do solo, hidromorfismo, subsidência, armazenamento de água.

(1) Parte da Dissertação de Mestrado do primeiro autor apresentada ao Curso de Pós-graduação em Agronomia - Solos e Nutrição de Plantas. Universidade Federal do Ceará - UFC. Fortaleza (CE). Projeto financiado pelo CNPq e CAPES. Recebido para publicação em 14 de novembro de 2012 e aprovado em 12 de setembro de 2013.

(2) Doutorando em Agronomia - Ciência do Solo e Nutrição de Plantas, Escola Superior de Agronomia "Luís de Queiroz" - ESALQ. Av. Pádua Dias, 11. Caixa Postal 9. CEP 13418-900. Piracicaba (SP). Bolsista Capes. E-mail: ciprorafael@yahoo.com.br

(3) Professor Adjunto III, Departamento de Geografia e História. Universidade Federal do Piauí - UFPI. Campus Universitário Ministro Petrônio Portella, Bairro Ininga. CEP 64049-550 Teresina (PI). E-mail: valladares@ufpi.edu.br

(4) Professor Associado IV, Departamento de Solos da Universidade Federal Rural do Rio de Janeiro - UFRRJ. BR 465, km 7. CEP 23890-000 Seropédica (RJ). Bolsistas Produtividade do CNPq e FAPERJ. E-mail: gervasio@ufrrj.br, lanjos@ufrrj.br 


\title{
SUMMARY: CHARACTERIZATION OF HISTOSOLS IN FLOODPLAIN ENVIRONMENTS IN THE NORTHEAST REGION OF BRAZIL
}

\begin{abstract}
The Histosols are generally associated with Southeastern and Southern regions of Brazil, and there are few studies on the occurrence and effects of the use and agricultural management of these soils in the Northeast. The aim of this paper is to physically, chemically and morphologically characterize six profiles of Histosols from flood plains in the states of Ceara, Rio Grande do Norte and Paraiba, Brazil and correlate their soil properties to the training environment, as well as quantify their carbon stores and water storage capacities. We used the methods recommended in the Brazilian System of Soil Classification (SiBCS) for chemical and physical characterization, moisture content and residual volume soil. The increase in the values of bulk density (BD) in the horizons was due to greater decomposition of rubbed fibers $(R F)$ and decrease in soil organic matter. Residual volume was positively and significantly (5\%) correlated with the minimum residual value $(r=0.64)$ and $B D(r=0.74)$ and negatively correlated with the percentage of $R F(r=-0.75)$, and it can be used to assess the subsidence of these soils. Chemical properties were affected by the material of organic origin and fluvialmarine sediments. Drainage variation, influenced by position in the landscape and crop use of the soils, led to classes with different degrees of decomposition of organic matter and, thus, Fibric, Hemic and Sapric classes of 'Organossolos'. One of the CE1 profiles, with greater influence from marine sediments, was classified as an 'Organossolo Tiomórfico' of a solodic nature.
\end{abstract}

Index terms: soil organic matter, hydromorphism, subsidence, water storage.

\section{INTRODUÇÃO}

A gênese dos Organossolos está associada a ambientes onde o acúmulo de resíduos orgânicos brutos é maior que a sua decomposição. Tal padrão pode ser observado em ambientes onde ocorrem condições anóxicas, provocadas pela saturação por água, baixas temperaturas, ou ainda onde a acidez ou concentração de sais são elevadas (Andriesse, 1988; Driessen, 2001; Chimner \& Ewel, 2005). Tais solos têm sido mais identificados nas regiões Sudeste e Sul do Brasil, estando relacionados aos ambientes de várzeas interioranas ou na baixada litorânea, ocorrendo ainda em ambiente altomontano. Na região Nordeste, a ocorrência de solos com elevados teores de matéria orgânica está associada principalmente a zonas litorâneas com influência marinha, várzeas de planícies de inundação, incluindo feições antigas de meandros abandonados, formações lacustres e vales fluviais (Andriesse, 1988; Pereira et al., 2005), sob vegetação de campos hidrófilos com tifáceas ou formações arbustivas e arbóreas paludosas, que proporcionam a grande produção de biomassa vegetal.

Apesar de já terem sido realizados estudos com o objetivo de caracterizar os Organossolos em alguns estados da região Nordeste do Brasil, como Bahia e Alagoas (Couto \& Resende, 1985; Souza Jr et al., 2001a,b; Pereira et al., 2006; Valladares et al., 2008a,b) e Maranhão (Ebeling et al., 2013), pouco são os estudos sobre a gênese e a ocorrência desses solos nos Estados do Ceará, do Rio Grande do Norte e da Paraíba. As áreas de turfeiras das planícies, com Organossolos de ambiente de várzea, influenciam na dinâmica e qualidade da água do ambiente. Tais áreas possuem elevada capacidade de retenção e armazenamento de água, além de atuarem no acúmulo de sedimentos, na detenção de nutrientes e na prevenção da erosão (Rieley et al., 2008). Esses ecossistemas também são reconhecidos por desempenharem papel importante no ciclo e sequestro de carbono atmosférico (Campos et al., 2012), contribuindo com cerca de $30 \%$ do carbono global estocado, além de atuarem nos processos ambientais associados às mudanças climáticas globais (Rieley et al., 2008).

Em virtude da grande fragilidade, esses ecossistemas são muito suscetíveis à degradação (Chimner \& Ewel, 2005), resultando em consequências como a alteração do regime hidrológico, o soterramento dos Organossolos pela deposição de sedimentos minerais com o assoreamento das depressões onde ocorrem, a mineralização e a redução dos teores de matéria orgânica e a subsidência (redução de volume e massa). Pode haver diminuição da capacidade de suporte hídrico, do potencial de uso e da ação de filtragem em razão da diminuição da carga hidráulica e da qualidade da água que abastece os aquíferos subterrâneos (Andriesse, 1988; Chimner \& Ewel, 2005; Valladares et al., 2008b).

Tendo em vista a importância desses ecossistemas, os objetivos deste estudo foram caracterizar, sob os pontos de vista morfológico, físico e químico, Organossolos de seis áreas de várzeas da Região Nordeste do Brasil; quantificar o estoque parcial de carbono; avaliar a capacidade de armazenamento de água; e correlacionar os atributos dos solos ao ambiente de formação, fornecendo elementos para a sua classificação. 


\section{MATERIAL E MÉTODOS}

\section{Meio físico}

As áreas de coleta foram identificadas com base em levantamentos realizados nos Estados do Rio Grande do Norte (Embrapa, 1971) e Paraíba (Embrapa, 1972), que apontam delineamentos de associações de Gleissolos com Organossolos. No Ceará, algumas áreas pontuais estão localizadas no campus da Universidade Federal do Ceará (UFC). Selecionaram-se seis perfis de solo, dois do Estado do Ceará (CE1 e CE2), dois do Rio Grande do Norte (RN1 e RN2) e dois da Paraíba (PB1 e PB2) (Quadro 1), que foram descritos e coletados em outubro de 2010.

O material de origem da área de coleta dos perfis é composto por depósitos de sedimentos Quaternários, de composição orgânica e mineral. Os sedimentos minerais são predominantemente argiloarenosos, de origem fluvial e, ou, marinha.

As áreas de coleta dos perfis CE1 e CE2 situam-se próximas a efluentes do rio Cocó e a manguezais. A região é caracterizada pelo clima Aw', tropical chuvoso quente-úmido com estação seca (Köppen), temperatura média máxima de $31{ }^{\circ} \mathrm{C}$ e mínima de $23{ }^{\circ} \mathrm{C}$ e pluviosidade variando de 880 a $2.200 \mathrm{~mm}$ ao ano. $\mathrm{O}$ perfil CE1 não possui uso agrícola, sendo a cobertura vegetal de gramíneas e convolvuláceas lianas. A área do perfil CE2 é destinada ao pastejo de caprinos, sendo observada intensa alteração antrópica, como abertura de valas de drenagem e revolvimento do solo.

Os perfis RN1 e RN2 encontram-se na planície de inundação da bacia dos rios Ceará-Mirim e Punaú, respectivamente. A área $\mathrm{RN} 1$ encontra-se em propriedade rural e é destinada ao cultivo de cana-deaçúcar há mais de 15 anos, com plantio de mandioca após a colheita. Também em propriedade rural, a área
RN2 é utilizada para lavoura de milho e abóbora, com uso há cerca de 30 anos. O perfil PB1 está localizado na planície da bacia do rio Ibiaí, destinada ao pastejo extensivo de bovinos, enquanto o perfil PB2 encontrase em um vale encaixado da Depressão Ibiaí, onde o relevo é suave ondulado. Nessa área são plantadas bananeiras, coqueiros, mandioca e hortaliças há mais de 25 anos.

Nas áreas localizadas no Rio Grande do Norte e na Paraíba, as condições climáticas são semelhantes. O clima é classificado como tropical chuvoso quente e úmido do tipo As', segundo Köppen, que demarca regiões de transição entre o ambiente litorâneo úmido e seco (Embrapa, 1972). A pluviosidade varia entre 1.200 e $1.600 \mathrm{~mm}$ ao ano.

Nesses ambientes, a vegetação original é de campo higrófilo de várzea nas periferias dos cursos d'água, comumente com a presença de espécies herbáceas de gramíneas, tifáceas e ciperáceas (Embrapa, 1971, 1972). Todos os perfis foram amostrados em várzeas e são muito mal- drenados ou foram drenados artificialmente.

\section{Métodos}

Os perfis foram descritos segundo Santos et al. (2005); amostras indeformadas e deformadas foram coletadas. Nas amostras dos horizontes hísticos, ainda com teores de umidade próximos dos obtidos no campo, foram determinados o teor de fibras esfregadas (FE) e o índice de pirofosfato (IP) (Embrapa, 2006). Após esses testes, as amostras foram secas ao ar e peneiradas (malha de $2 \mathrm{~mm}$ ) para obtenção da terra fina seca ao ar (TFSA).

Utilizou-se um método para avaliar a subsidência a partir da determinação do volume residual (VR) utilizando cilindros de PVC com 1,5 polegadas de diâmetro e com altura de $5 \mathrm{~cm}$, que foram inseridos nos horizontes hísticos no sentido perpendicular. Após a coleta, foi eliminado o excesso de solo das extremidades

Quadro 1. Perfis, localização e características das áreas com Organossolos localizados nos Estados do Ceará, Rio Grande do Norte e Paraíba

\begin{tabular}{|c|c|c|c|c|c|}
\hline Perfil & Localização & $\begin{array}{l}\text { Coordenada } \\
\text { geográfica }\end{array}$ & Alt. & Ambiente de formação & $\begin{array}{l}\text { Altura do } \\
\text { lençol freático }\end{array}$ \\
\hline & & & $\mathrm{m}$ & & $\mathrm{cm}$ \\
\hline CE1 & Fortaleza, CE & $\begin{array}{l}38^{\circ} 34^{\prime} 23^{\prime \prime} \mathrm{W} \\
3^{\circ} 44^{\prime} 21^{\prime \prime} \mathrm{S}\end{array}$ & 16 & $\begin{array}{l}\text { Campos de várzea, sedimentos orgânicos } \\
\text { (Holoceno) e argilosos }\end{array}$ & 41 \\
\hline $\mathrm{CE} 2$ & Fortaleza, CE & $\begin{array}{l}38^{\circ} 34^{\prime} 54^{\prime \prime} \mathrm{W} \\
3^{\circ} 44^{\prime} 32^{\prime \prime} \mathrm{S}\end{array}$ & 13 & $\begin{array}{c}\text { Campos de várzea, sedimentos orgânicos } \\
\text { (Holoceno) e argiloarenosos }\end{array}$ & 40 \\
\hline RN1 & Ceará-Mirim, RN & $\begin{array}{l}35^{\circ} 23^{\prime} 57^{\prime \prime} \mathrm{W} \\
5^{\circ} 36^{\prime} 21^{\prime \prime} \mathrm{S}\end{array}$ & 5 & $\begin{array}{c}\text { Campos de várzea, sedimentos orgânicos } \\
\text { (Holoceno) }\end{array}$ & 30 \\
\hline $\mathrm{RN} 2$ & Rio do Fogo, RN & $\begin{array}{l}35^{\circ} 24^{\prime} 46^{\prime \prime} \mathrm{W} \\
5^{\circ} 22^{\prime} 27^{\prime \prime} \mathrm{S}\end{array}$ & 13 & $\begin{array}{c}\text { Campos de várzea, sedimentos orgânicos } \\
\text { (Holoceno) }\end{array}$ & 40 \\
\hline $\mathrm{PB} 1$ & Alhandra, PB & $\begin{array}{l}34^{\circ} 52^{\prime} 44^{\prime \prime} \mathrm{W} \\
7^{\circ} 26^{\prime} 25^{\prime \prime} \mathrm{S}\end{array}$ & 4 & $\begin{array}{c}\text { Campos de várzea, sedimentos orgânicos } \\
\text { (Holoceno) e argilosos }\end{array}$ & 28 \\
\hline PB2 & Caaporã, PB & $\begin{array}{c}34^{\circ} 53^{\prime} 39^{\prime \prime} \mathrm{W} \\
7^{\circ} 30^{\prime} 03^{\prime \prime} \mathrm{S}\end{array}$ & 6 & $\begin{array}{c}\text { Campos de várzea, sedimentos orgânicos } \\
\text { (Holoceno) }\end{array}$ & 50 \\
\hline
\end{tabular}

Alt.: altitude. 
dos anéis. Os cilindros foram envolvidos em papel-filme para, no campo, determinar a massa e o volume inicial. Em laboratório, as amostras foram secas ao ar até atingir massa constante, sendo posteriormente secas em estufa a $65{ }^{\circ} \mathrm{C}$ por $48 \mathrm{~h}$ e em seguida obtidos a massa e o volume final. O volume residual (VR) foi calculado por meio da relação entre o volume final da amostra e o volume inicial, expresso em porcentagem. A densidade do solo (Ds) foi calculada a partir do teste de VR, utilizando a massa da amostra seca em estufa a $65^{\circ} \mathrm{C}$ e o volume do cilindro. Foram determinadas a densidade das partículas $(\mathrm{Dp})$, a umidade gravimétrica (Ug), o espaço poroso saturado por água (EPSA) e o volume total de poros (VTP) (Embrapa, 1997).

Com base na umidade volumétrica, foi calculado o volume de água armazenado no perfil de solo até $0,50 \mathrm{~m}$ de profundidade. $\mathrm{O}$ estoque de carbono (C) no solo (em Mg ha ${ }^{-1}$ de C) até $0,50 \mathrm{~cm}$ de espessura foi calculado multiplicando-se o teor de $\mathrm{C}$ orgânico (CO) de cada horizonte pela Ds.

O teor de matéria orgânica (MO) foi quantificado pelo método de perda de massa por incineração a $600{ }^{\circ} \mathrm{C}$ em mufla, conforme Pereira et al. (2006) e Embrapa (2006). Foram quantificados a densidade da matéria orgânica (DMO), o resíduo mínimo (RM) e o material mineral (MM), segundo Lynn et al. (1974), citado por Embrapa (2006).

Para a caracterização química, foram determinados os valores de $\mathrm{pH}$ (água e $\mathrm{KCl} 1 \mathrm{~mol} \mathrm{~L}^{-1}, 1: 2,5$ ), o complexo sortivo ( $\mathrm{Ca}, \mathrm{Mg}, \mathrm{K}, \mathrm{Na}, \mathrm{H}$ e $\mathrm{Al}$ ), o $\mathrm{P}$ disponível, os micronutrientes ( $\mathrm{Fe}, \mathrm{Mn}, \mathrm{Zn}$ e $\mathrm{Cu}$ ) e o equivalente carbonato de cálcio (Embrapa, 1997). O teor de $\mathrm{P}$ também foi determinado com uso de solução de bicarbonato de sódio (Olsen et al., 1954).

Os atributos físicos e químicos foram analisados com base em técnicas de estatística descritiva, análises de regressão linear simples e correlação de Pearson, a $5 \%$. A análise de componentes principais (ACP) foi realizada por meio do programa estatística XLStat, cujas variáveis foram as que apresentaram correlações de Pearson maiores que 0,5 entre si, relacionadas a seguir: VR, RM, MM, FE, MO, Ds e DMO. A ACP é utilizada para reduzir as dimensões dos dados e, consequentemente, facilitar a análise por meio do gráfico do círculo de correlação (Herlihy \& McCarthy, 2006). Com base nos atributos morfológicos, químicos e físicos, os perfis de solo foram classificados segundo o Sistema Brasileiro de Classificação de Solos até o quarto nível categórico (Embrapa, 2006).

\section{RESULTADOS E DISCUSSÃO}

\section{Aspectos morfológicos}

A descrição dos perfis (Quadro 2) apresenta diferenças nos perfis estudados, principalmente na espessura dos horizontes e no grau de decomposição da matéria orgânica, avaliada no campo pelo teste de von Post (VP) (Embrapa, 2006) (Quadro 3), cujos valores da escala variam de 1 (material orgânico não decomposto) a 10 (material orgânico completamente decomposto).

Alguns horizontes hísticos apresentam escurecimento do material quando exposto ao ar, imediatamente após a coleta das amostras. Por essa razão, as cores das amostras foram identificadas antes e depois da oxidação ao ar. O horizonte Hdo1 do perfil $\mathrm{RN} 1$ evidencia maior variação do matiz, cujas cores alteram da página 2,5YR a 10YR após oxidação; e o croma muda em até uma unidade. Variações do croma foram maiores nos horizontes Hoj, Ho e Hdo dos perfis CE1, CE2 e PB2, respectivamente, variando até duas unidades, enquanto o matiz varia apenas uma página no perfil RN2 (5YR a 2,5YR). Essa alteração na cor foi verificada nos horizontes que evidenciavam menor grau de decomposição da matéria orgânica. Tais horizontes ocorrem em profundidade maior que $21 \mathrm{~cm}$ (Perfil CE1, horizonte Hoj) e apresentam maior saturação por água. Nos horizontes Cg, predominam cores acinzentadas, indicativo do processo de gleização, por vezes com baixos valores (Cg e Cgn do perfil CE1) em virtude da presença de material orgânico em meio ao material mineral, o que pode ser ratificado em razão dos teores de $\mathrm{FE}$ verificados nesses horizontes (Quadro 3). O horizonte Cgj do perfil CE2 apresenta coloração variegada, o que confirma a condição sazonal de oscilação do lençol freático.

Nos horizontes orgânicos mais superficiais predominam estruturas granulares com grau de desenvolvimento variando de fraco a forte. A condição de umidade ou saturação prolongada nos horizontes subsuperficiais, observado por meio dos valores de espaço poroso saturado por água (EPSA) (Quadro 3), impede a formação de agregados. A estrutura predominante em todos os horizontes é a maciça com fibras, compatível com o maior teor de fibras e o baixo grau de decomposição do material orgânico. Atributos semelhantes foram observados para Organossolos de outros estados brasileiros (Souza Jr et al., 2001a; Valladares et al., 2008a).

\section{Atributos físicos e matéria orgânica}

Os valores de densidade do solo (Ds) variam de 0,09 a $1,67 \mathrm{Mg} \mathrm{m}^{-3}$ e mediana de $0,26 \mathrm{Mg} \mathrm{m}^{-3}$ (Quadro 3). As variações observadas possuem correlação inversa e significativa a $5 \%$ aos teores de fibras esfregadas $(\mathrm{FE})(\mathrm{r}=-0,62$; valores não apresentados) e de matéria orgânica (MO) $(r=-0,81)$ e correlação positiva com o teor de material mineral (MM) $(r=0,84)$. Dessa forma, o menor valor de Ds deve-se ao aumento do teor de $\mathrm{MO}$, ao menor grau de decomposição da $\mathrm{MO}$ e à menor proporção da fração mineral, resultando em maior porosidade pelos espaços entre as estruturas do material fíbrico. Resultados semelhantes foram obtidos por Souza Jr et al. (2001a) e Campos et al. (2011a) em Organossolos de Alagoas e Minas Gerais, 
respectivamente. Nichols \& Boelter (1984) identificaram forte correlação entre Ds e grau de decomposição do material orgânico, onde o tamanho e a quantidade de fibras foram responsáveis pelo aumento da Ds.

Ao mesmo tempo, quanto maior a subsidência, inferida pelos valores de resíduo mínimo (RM), maiores os valores de $\mathrm{Ds}(\mathrm{r}=0,99)$ e de material mineral $(\mathrm{MM})(\mathrm{r}=0,88)$. O perfil $\mathrm{RN} 1$ possui o maior RM $\left(0,48 \mathrm{~cm} \mathrm{~cm}^{-1}\right)$ em superfície, seguido do CE2 $\left(0,46 \mathrm{~cm} \mathrm{~cm}^{-1}\right)$ e RN2 $\left(0,32 \mathrm{~cm} \mathrm{~cm}^{-1}\right)$, cujos valores observados são maiores que os obtidos por Nascimento et al. (2010) em horizontes Hísticos de solos hidromórficos do Espírito Santo. Assim, a maior proporção de material mineral nos horizontes orgânicos pode ser efeito da oxidação do material orgânico, em virtude da drenagem e do uso agrícola.

Os valores elevados de densidade da matéria orgânica (DMO) encontrados nos horizontes superficiais nos perfis RN1 e RN2 (0,19 e 0,21 $\mathrm{Mg} \mathrm{m}^{-3}$, respectivamente) também são um indicativo do uso agrícola nessas duas áreas (há mais de 15 anos), corroborando com a afirmação relatada anteriormente e de Ebeling et al. (2013), os quais, avaliando oito

Quadro 2. Atributos morfológicos dos perfis de Organossolos localizados nos Estados do Ceará, Rio Grande do Norte e da Paraíba

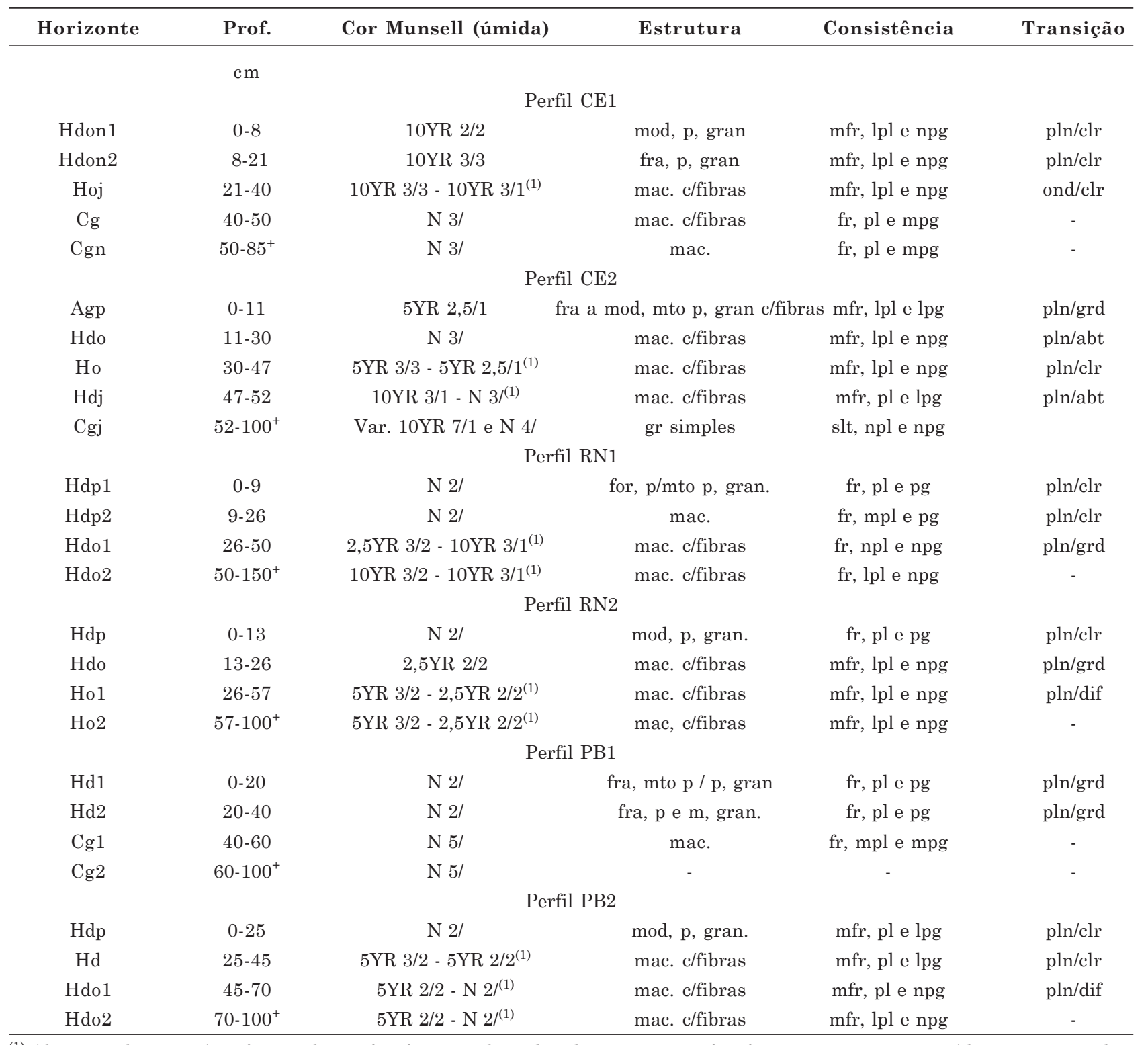

(1) Alteração da cor após sofrer oxidação; for: forte; mod: moderada; mto: muito; fra: fraca; p: pequena; m: média; gran: granular; mac: maciço; slt: solta; mfr: muito friável, fr: friável; npl: não plástica; lpl: ligeiramente plástica; pl: plástica; mpl: muito plástica; npg: não pegajosa; lpg: ligeiramente pegajosa; pg: pegajosa; mpg: muito pegajosa. pln: plana; ond: ondulada; abt; abrupta; clr: clara; grd: gradual; e dif: difusa. 
perfis de diferentes regiões do Brasil, observaram valores de DMO variando de 0,02 a $0,66 \mathrm{Mg} \mathrm{m}^{-3}$. Valores de DMO acima de $0,07 \mathrm{Mg} \mathrm{m}^{-3}$ foram relacionados a solos submetidos a maior intensidade de cultivo (Lynn et al., 1974).

Um atributo usado também para a caracterização física e para avaliar a suscetibilidade à subsidência foi o percentual do volume residual do solo (VR), cujos valores variam de 12 a $91 \%$ e a mediana de $28 \%$. A diminuição do grau de decomposição do material orgânico, associado aos maiores teores de FE, e o aumento dos teores de MO favorecem a redução do
VR, ou seja, é maior a contração do solo pós-secagem, podendo inferir maior risco de subsidência, como observado no horizonte Hdon1 (perfil CE1), que apresenta os menores valores de VR em superfície, aumentando em profundidade. As amostras com menor VR evidenciam maior porosidade e, portanto, maior capacidade de armazenar água $(r=-0,78)$. Nos horizontes superficiais, já submetidos à drenagem e com maior grau de decomposição, o volume do solo foi reduzido ao longo do tempo e por isso demonstram os maiores valores de VR. Segundo Dawson et al. (2010), materiais orgânicos menos decompostos são mais

Quadro 3. Valores atributos físicos e teores de matéria orgânica de Organossolos localizados nos Estados do Ceará, do Rio Grande do Norte e da Paraíba

\begin{tabular}{|c|c|c|c|c|c|c|c|c|c|c|c|c|c|}
\hline Horizonte & Dp & Ds & VTP & $\mathbf{U g}$ & EPSA & MO & MM & DMO & $\mathbf{R M}$ & FE & IP & VP & VR \\
\hline & \multicolumn{2}{|c|}{$\mathrm{Mg} \mathrm{m}^{-3}$} & $\mathrm{~m}^{3} \mathrm{~m}^{-3}$ & $\mathrm{~g} \mathrm{~g}^{-1}$ & $\%$ & $\mathrm{~g} \mathrm{~kg}^{-1}$ & $\%$ & $\mathrm{mg} \mathrm{m}^{-3}$ & $\mathrm{~cm} \mathrm{~cm}^{-1}$ & $\%$ & & & $\%$ \\
\hline & & & & & & Perfil & & & & & & & \\
\hline Hdon 1 & 1,78 & 0,13 & 0,93 & 5,7 & 78,9 & 504,00 & 33,4 & 0,09 & 0,03 & 32 & 1 & 5 & 12 \\
\hline Hdon2 & 1,66 & 0,13 & 0,92 & 6,6 & 90,1 & 504,00 & 35,6 & 0,08 & 0,03 & 40 & 3 & 3 & 18 \\
\hline Hoj & 1,49 & 0,16 & 0,89 & 5,3 & 92,4 & 534,50 & 39,1 & 0,10 & 0,04 & 46 & 6 & 4 & 22 \\
\hline $\mathrm{Cg}$ & 2,24 & 0,92 & 0,59 & 0,6 & 98,6 & 132,00 & 86,1 & 0,13 & 0,53 & 16 & 5 & 8 & 60 \\
\hline \multirow[t]{2}{*}{ Cgn } & 2,39 & - & - & - & - & 94,00 & 90,2 & - & - & - & - & - & - \\
\hline & & & & & & \multicolumn{2}{|c|}{ Perfil CE2 } & & & & & & \\
\hline Agp & 2,05 & 0,79 & 0,61 & 0,7 & 90,6 & 118,00 & 87,7 & 0,10 & 0,46 & 28 & 1 & 7 & 40 \\
\hline Hdo & 2,17 & 0,51 & 0,77 & 1,4 & 91,6 & 164,50 & 82,8 & 0,09 & 0,28 & 32 & 0 & 8 & 60 \\
\hline Ho & 1,62 & 0,09 & 0,94 & 9,2 & 92,1 & 511,50 & 36,5 & 0,06 & 0,02 & 48 & 7 & 3 & 16 \\
\hline Hdj & 2,29 & 0,31 & 0,86 & 2,6 & 94,2 & 207,00 & 77,7 & 0,07 & 0,16 & 24 & 5 & 9 & 25 \\
\hline \multirow[t]{2}{*}{$\mathrm{Cg}$} & 2,53 & 1,47 & 0,34 & 0,2 & 99,7 & 12,00 & 98,8 & 0,02 & 1,10 & - & - & - & - \\
\hline & & & & & & \multicolumn{2}{|c|}{ Perfil RN1 } & & & & & & \\
\hline Hdp1 & 2,43 & 0,90 & 0,63 & 0,6 & 84,1 & 174,50 & 79,1 & 0,19 & 0,48 & 8 & 0 & 10 & 57 \\
\hline Hdp2 & 2,31 & 0,65 & 0,72 & 1,1 & 98,7 & 180,50 & 78,1 & 0,14 & 0,34 & 8 & 0 & 10 & 43 \\
\hline Hdo1 & 1,68 & 0,11 & 0,94 & 7,0 & 79,6 & 472,00 & 38,7 & 0,07 & 0,03 & 32 & 3 & 6 & 19 \\
\hline \multirow[t]{2}{*}{ Hdo2 } & 1,71 & 0,13 & 0,92 & 5,9 & 83,0 & 496,00 & 38,0 & 0,08 & 0,03 & 26 & 5 & 5 & 19 \\
\hline & & & & & & \multicolumn{2}{|c|}{ Perfil RN2 } & & & & & & \\
\hline Hdp & 2,03 & 0,70 & 0,66 & 0,5 & 56,2 & 248,00 & 69,8 & 0,21 & 0,32 & 10 & 0 & 10 & 91 \\
\hline Hdo & 1,39 & 0,10 & 0,93 & 8,7 & 97,3 & 722,50 & 15,9 & 0,09 & 0,01 & 40 & 1 & 4 & 28 \\
\hline Ho1 & 1,35 & 0,15 & 0,89 & 5,8 & 97,2 & 741,50 & 15,1 & 0,13 & 0,02 & 42 & 6 & 3 & 26 \\
\hline \multirow[t]{2}{*}{ Ho2 } & 1,30 & 0,10 & 0,92 & 9,3 & 100,4 & 732,50 & 16,8 & 0,08 & 0,01 & 44 & 7 & 2 & 13 \\
\hline & & & & & & \multicolumn{2}{|c|}{ Perfil PB1 } & & & & & & \\
\hline Hd1 & 2,24 & 0,31 & 0,86 & 2,1 & 76,9 & 211,0 & 73,4 & 0,08 & 0,15 & 16 & 1 & 10 & 69 \\
\hline Hd2 & 2,15 & 0,63 & 0,71 & 0,9 & 81,0 & 163,0 & 80,6 & 0,12 & 0,34 & 8 & 0 & 10 & 65 \\
\hline $\mathrm{Cg} 1$ & 2,70 & 1,10 & 0,59 & 0,5 & 94,7 & 75,0 & 92,0 & 0,09 & 0,67 & - & - & - & - \\
\hline \multirow[t]{2}{*}{$\mathrm{Cg} 2$} & 2,64 & - & - & - & - & 12,5 & 98,7 & - & - & - & - & - & - \\
\hline & & & & & & \multicolumn{2}{|c|}{ Perfil PB2 } & & & & & & \\
\hline Hdp & 1,19 & 0,36 & 0,70 & 1,7 & 88,8 & 572,50 & 21,9 & 0,28 & 0,05 & 2 & 1 & 10 & 80 \\
\hline $\mathrm{Hd}$ & 1,45 & 0,20 & 0,86 & 3,7 & 88,6 & 480,50 & 31,0 & 0,14 & 0,04 & 4 & 0 & 7 & 43 \\
\hline Hdo1 & 1,25 & 0,14 & 0,89 & 5,9 & 94,1 & 734,00 & 13,6 & 0,12 & 0,01 & 24 & 0 & 5 & 29 \\
\hline Hdo2 & 1,57 & 0,09 & 0,94 & 9,3 & 86,9 & 416,00 & 13,1 & 0,08 & 0,01 & 40 & 4 & 4 & 27 \\
\hline
\end{tabular}

Dp: densidade das partículas; Ds: densidade do solo; VTP: volume total de poros; Ug: umidade gravimétrica; EPSA: espaço poroso saturado por água; MO: matéria orgânica (mufla); MM: material mineral; DMO: densidade da matéria orgânica; RM: resíduo mínimo. FE: fibras esfregadas; IP: índice de pirofosfato; VP: classes de decomposição de von Post; e VR: volume residual. 
propensos à contração e mineralização, resultando na perda de volume irreversível em razão da drenagem excessiva e consequentemente da subsidência.

Para uma melhor compreensão da relação entre os atributos físicos do solo e os relacionados à matéria orgânica do solo, efetuou-se a análise de componentes principais (ACP). Foram geradas duas componentes principais (fator 1 e fator 2) para DMO, MO, VR, FE, DS, RM e MM. Verificou-se que a distribuição das variáveis selecionadas apresentou variância acumulada de $89,76 \%$ para os eixos F1 (Componente 1) e F2 (Componente 2); o eixo F1 foi capaz de explicar 67,69 \% e o F2 22,07 \% dessa variância (Figura 1). Verifica-se que os valores de DMO e VR correlacionaramse inversamente com os teores de $\mathrm{FE}$, sendo esse padrão também observado para os teores de MO e Ds, RM e MM. O VR apresentou correlação positiva com o RM $(r=0,64)$, Ds $(r=0,74)$ e MM $(r=0,53)$. Ainda, os valores percentuais do VR possuem correlação inversa com FE $(\mathrm{r}=-0,75)$ e $\mathrm{MO}(\mathrm{r}=-0,55)$, indicando que a variável está fortemente associada ao grau de decomposição do material orgânico que ao RM.

A partir do exposto, verifica-se que outros estudos devem ser conduzidos para validar a eficácia do VR, relacionando-o com outros atributos, bem com buscar inferências a respeito do seu uso para avaliação do grau de subsidência e até mesmo auxiliar a classificação dos Organossolos.

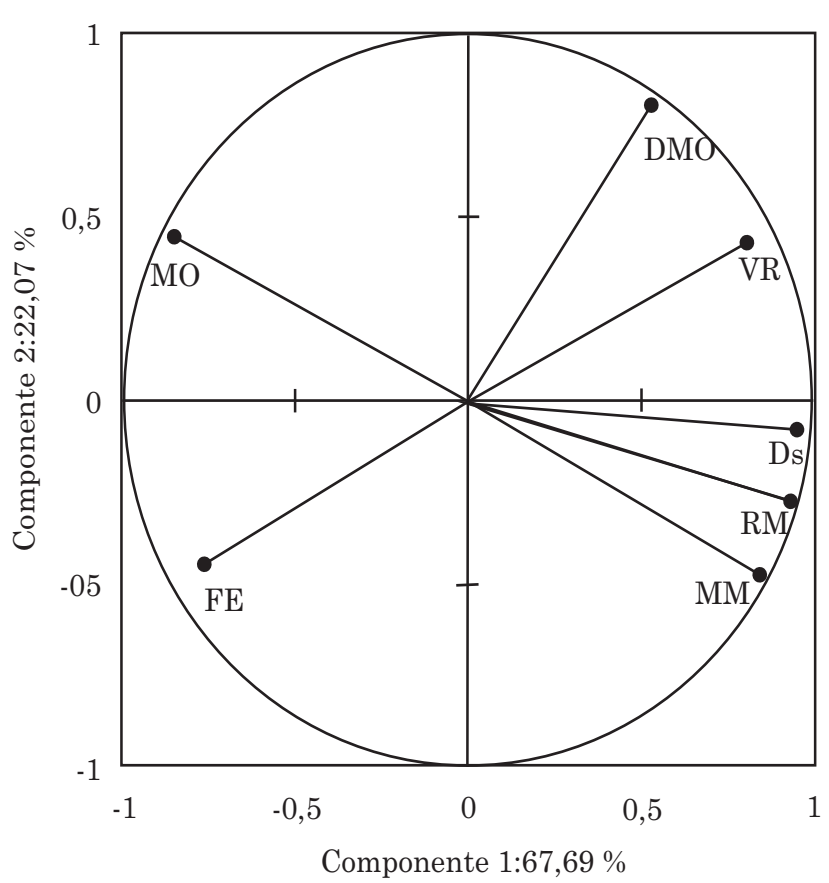

Figura 1. Diagrama de ordenação produzido por análise de componentes principais dos atributos do solo: densidade da matéria orgânica (DMO), volume residual (VR), densidade do solo (Ds), resíduo mínimo (RM), material mineral (MM), fibras esfregadas (FE) e matéria orgânica (MO).

\section{Armazenamento de água e estoque de carbono}

Os Organossolos possuem elevada capacidade de armazenamento de água, como observado pelos valores de umidade gravimétrica (Ug), com até $930 \%$ (horizontes Ho2 e Hdo2 dos perfis RN2 e PB2, respectivamente). Esse padrão indica que esses solos são importantes reservatórios de água. O material orgânico menos decomposto, em que se verifica maior valor de (FE) apresenta maior porosidade total (VTP) $(r=0,67)$, e maiores valores de $\mathrm{Ug}(r=0,78)$. No entanto, o volume de água armazenado nos perfis não evidenciou correlação significativa com os percentuais de FE, mas com os teores de MO $(r=0,46)$, demonstrando que o teor de material orgânico é mais relevante no armazenamento de água que o grau de decomposição desse. Silva et al. (2009) e Campos et al. (20011a) destacaram que o teor e o estádio de decomposição da matéria orgânica influenciam na capacidade de armazenamento de água em Organossolos.

Avaliando o volume de água armazenado até $0,50 \mathrm{~m}$ de profundidade, observa-se valor máximo de $3.821,8 \mathrm{~m}^{-3} \mathrm{ha}^{-1}$ em CE1 e mínimo de $3.031,4 \mathrm{~m}^{-3} \mathrm{ha}^{-1}$ em PB1 (Figura 2a). Campos et al. (2011a) quantificam um valor médio de $6.092,0 \mathrm{~m}^{-3} \mathrm{ha}^{-1}$ de água em Organossolos localizados de Diamantina, MG.

A fim de estimar os potenciais de estoque de $\mathrm{C}$ nos perfis, foi calculada a quantidade de carbono orgânico (CO) até a profundidade amostrada (Figura 2b). O CE2
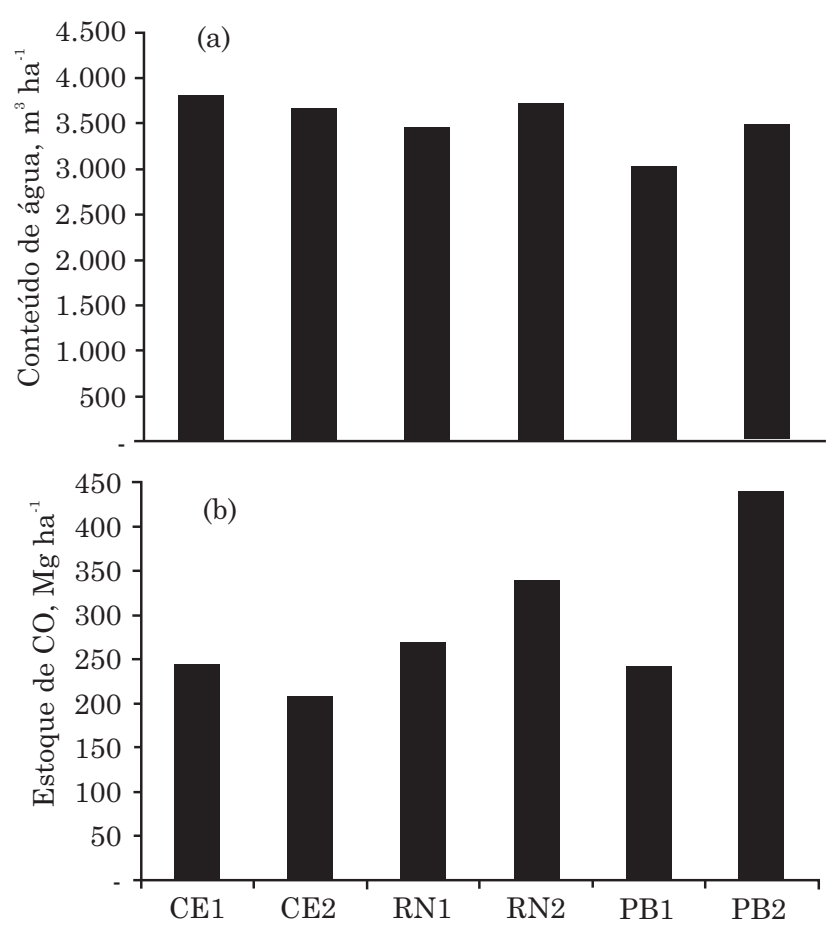

Figura 2. Capacidade de armazenamento de água (a) e estoque de carbono orgânico (b) dos perfis de solo a uma profundidade de $0,50 \mathrm{~m}$ de Organossolos localizados nos Estados do Ceará, do Rio Grande do Norte e da Paraíba. 
possui menor estoque de $\mathrm{CO}$, com $208,45 \mathrm{Mg}^{-1}$, enquanto PB2 apresenta os maiores valores de C $\left(440,18 \mathrm{Mg} \mathrm{ha}^{-1}\right)$. Scheer et al. (2011) obtiveram valores de estoque de CO variando de 274,3 a $410,6 \mathrm{Mg} \mathrm{ha}^{-1}$ em Organossolos de campos altomontanos, enquanto as florestas apresentaram valores menores $(190,1 \mathrm{a}$ $\left.233,4 \mathrm{Mg} \mathrm{ha}^{-1} \mathrm{C}\right)$. No entanto, para uma estimativa precisa dos valores de estoque de CO, são necessários levantamentos das áreas de ocorrência desses solos, uma vez que são comuns diferenças significativas nos estoques de $\mathrm{C}$ decorrentes das diferenças entre os solos, a topografia e as características do material orgânico.

\section{Atributos químicos}

Os valores de $\mathrm{pH}\left(\mathrm{H}_{2} \mathrm{O}\right)$ oscilam entre 3,0 e 7,6 , e mediana de 5,0, com valores maiores que os de $\mathrm{pH}$ em $\mathrm{KCl}$ (variação de 2,9 a 7,1, e mediana de 4,6) (Quadro 4). Foi observada correlação positiva entre os valores de $\mathrm{pH}\left(\mathrm{H}_{2} \mathrm{O}\right)$ e em $\mathrm{KCl}(\mathrm{r}=0,99)$, sugerindo que ambos os métodos são eficazes na determinação do $\mathrm{pH}$ em solos com elevados teores de MO.

Os perfis CE1 e CE2 apresentaram horizontes com valores de $\mathrm{pH}\left(\mathrm{H}_{2} \mathrm{O}\right)$ inferiores a 3,5, característica que denota a presença de materiais sulfídricos decorrentes do processo de sulfidização. No horizonte Hdj do perfil CE2, a presença desse material confere aos horizontes adjacentes Ho e $\mathrm{Cg}$ por causa dos baixos valores de $\mathrm{pH}(3,6)$.

Os maiores valores de $\mathrm{pH}$ nos horizontes superficiais foram encontrados no perfil RN1 $(7,6)$, o que pode ser atribuído, em parte, pela formação geológica da região, que apresenta vestígios de material calcário da Formação Jandaíra próximo à área de coleta dos perfis (Diniz Filho, 2000). Valores elevados de $\mathrm{pH}\left(\mathrm{H}_{2} \mathrm{O}\right)$ em Organossolos brasileiros são raros. Valladares et al. (2008a) em um estudo com 254 horizonte de Organossolos no Brasil não verificaram valores superiores a 6,5 .

Embora tenham sido constatados elevados valores de $\mathrm{Al}^{3+}$, a matéria orgânica complexa o $\mathrm{Al}^{3+}$ em seus radicais carboxílicos e fenólicos, reduzindo o efeito de toxidez aos vegetais. Valladares et al. (2008a) em seus estudos encontraram Organossolos com teores de $\mathrm{Al}^{3+}$ superiores até a $50 \mathrm{cmol}_{\mathrm{c}} \mathrm{kg}^{-1}$. Porém o método aplicado pode estar superestimando os teores de $\mathrm{Al}$ nas amostras, pois parte do $\mathrm{H}^{+}$proveniente dos radicais carboxílicos e fenólicos da $\mathrm{MO}$ pode estar sendo quantificado. Campos et al. (2011b) afirmaram que a determinação de $\mathrm{Al}^{3+}$ em espectrofotômetro de absorção atômica (EAA) é mais adequado em Organossolos.

Os valores de soma de bases foram elevados, prevalecendo os cátions $\mathrm{Ca}^{2+} \mathrm{e} \mathrm{Mg}^{2+}$ em relação aos demais, provavelmente em razão da influência do material calcário da Formação Gramame, presente próximo das áreas dos perfis PB1 e PB2 (Furrier et al., 2006; Neves et al., 2009) e do material calcário da formação Jandaíra na área do perfil RN1.
Os teores de $\mathrm{K}^{+}$mais elevados foram observados no perfil $\mathrm{CE} 1$, o que pode decorrer da influência flúviomarinha, das oscilações e da estagnação por água do lençol freático, contribuindo para o fornecimento de íons para o solo. Embora os materiais de solos orgânicos apresentem alta capacidade de troca catiônica do solo (CTC), correspondente ao valor T apresentado no quadro 4 , os teores de $\mathrm{K}^{+}$são geralmente baixos em razão da baixa capacidade de reter cátions monovalentes como $\mathrm{K}^{+} \mathrm{e} \mathrm{Na}^{+}$, já que se trata de ligações fracas (Lucas, 1982), exceto quando há influência marinha. Essa afirmação pode ser constatada pelos valores de correlação não significativos entre o valor $\mathrm{T}$ e os teores de $\mathrm{Na}^{+}$e $\mathrm{K}^{+}$. Também foi observado no perfil CE1 valores de saturação por sódio de 6 (Cgn) e 14 \% (Hdon1), conferindo o caráter solódico (Embrapa, 2006).

Os solos apresentaram valores elevados de CTC em virtude dos altos teores de MO, com correlação positiva entre esse atributo e os valores de $\mathrm{MO}(\mathrm{r}=0,80)$. Os elevados valores $\mathrm{S}$ se devem, em parte, aos teores

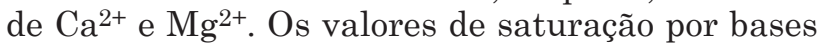
(V\%) foram elevados, acima de $50 \%$, porém não evidenciaram correlação significativa com os teores

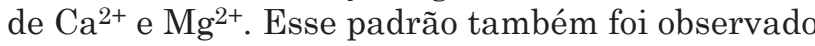
por Prada-Gamero et al. (2004) e Souza Jr. et al. (2001a).

Os valores de $\mathrm{P}$ (Mehlich-1) são irregulares, tanto em profundidade como entre os perfis, variando de 2 a $88 \mathrm{mg} \mathrm{kg}^{-1}$ e mediana de $9 \mathrm{mg} \mathrm{kg}^{-1}$, possivelmente por causa da capacidade de moléculas orgânicas de adsorver ânions fosfato, formando compostos pouco solúveis (Andriesse, 1988). Em razão dos baixos valores de equivalente $\mathrm{CaCO}_{3}$, com mediana de 1,3, assumese a pouca influência do $\mathrm{P}$ como fosfatos de cálcio, que poderia superestimar os teores de $\mathrm{P}$ por este método. Comparativamente, os teores de $\mathrm{P}$ pelo método de Olsen são menores que os obtidos pelo extrator duplo ácido. Foi identificada elevada correlação entre os valores obtidos pelos dois extratores $(r=0,82)$. Esse padrão indica que a quantificação dos teores de $\mathrm{P}$ em solos orgânicos com o extrator de Olsen $\left(\mathrm{NaHCO}_{3}\right)$ possibilita avaliar o $\mathrm{P}$ mais facilmente disponível para as plantas.

Quanto aos micronutrientes (Quadro 5), observase um padrão similar para os teores de Mn e Fe nos perfis, explicado pela maior solubilidade desses elementos em ambiente redutor. As variações encontradas nos teores de Mn foram de 0,17 e 83,33 $\mathrm{mg} \mathrm{kg}^{-1}$, com mediana de $16,28 \mathrm{mg} \mathrm{kg}^{-1}$. Yonebayashi et al. (1994) observaram em Organossolos da Tailândia e Malásia valores elevados de Mn, variando entre 3,4 e 183,0 $\mathrm{mg} \mathrm{kg}^{-1}$.

Os teores de Fe são maiores em relação aos demais metais, variando de 0,75 a $3.768,15 \mathrm{mg} \mathrm{kg}^{-1}$ e mediana de $141,42 \mathrm{mg} \mathrm{kg}^{-1}$. Os teores mais elevados foram verificados nos perfis $\mathrm{CE} 1$ e CE2, que têm menor $\mathrm{pH}$, o que pode ser indicativo da presença de pirita nesses solos. Esses valores são justificados em parte pela abundância de compostos de $\mathrm{Fe}$, de ocorrência natural 
nos solos (óxidos e hidróxidos), que são solubilizados; e os cátions reduzidos e liberados em ambientes permanentemente úmidos. Também, os teores de $\mathrm{Fe}$ apresentaram correlação significativa com os valores de $\mathrm{pH}$ do solo $(\mathrm{r}=0,51)$.

Os teores de $\mathrm{Cu}$ variaram de 0,00 a $6,03 \mathrm{mg} \mathrm{kg}^{-1}$, com mediana de $0,26 \mathrm{mg} \mathrm{kg}^{-1}$. Em condição de $\mathrm{pH}$ elevado, o $\mathrm{Cu}$ tem forte afinidade com compostos orgânicos, formando quelatos e por isso possuem menor disponibilidade em razão da baixa solubilidade. Por essa razão, os valores de $\mathrm{Cu}$ são menores que os dos outros metais, podendo até mesmo haver deficiência desse em plantas cultivadas em áreas de Organossolos (Kang \& Osiname, 1985; Andriesse, 1988; Yonebayashi et al.,1994). Em estudo sobre a adsorção de $\mathrm{Cu}$ e Zn em amostras de turfa, Lamim et al. (2001) verificaram máxima adsorção do Zn quando os valores de $\mathrm{pH}$ foram de 5,5. No entanto, a presença do íon competidor $\mathrm{Cu}$ interferiu na adsorção desse metal em $66 \%$. Isso pode explicar os maiores teores de $\mathrm{Zn}$ nos solos, comparados ao $\mathrm{Cu}$. Ainda, segundo os autores, a estabilidade do quelato formado é influenciada pelo número de átomos que se ligam ao íon metálico e

Quadro 4. Caracterização química dos Organossolos localizados nos Estados do Ceará, do Rio Grande do Norte e da Paraíba

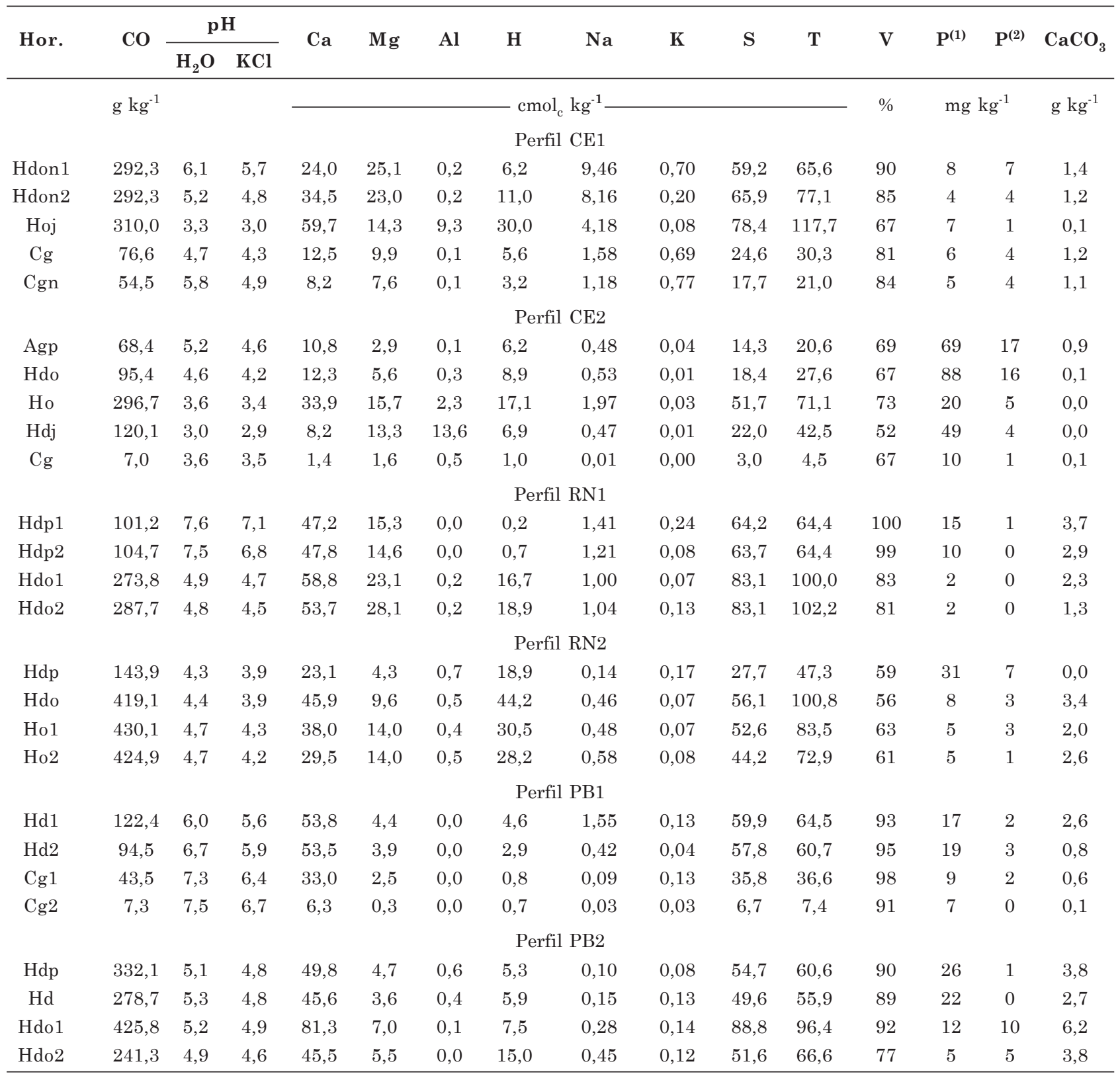

(1) P extraído por Mehlich-1; ${ }^{(2)} \mathrm{P}$ extraído por Olsen; CO: carbono orgânico; Valor S: soma de bases $\left(\mathrm{Ca}^{2+}+\mathrm{Mg}^{2+}+\mathrm{Na}^{+}+\mathrm{K}^{+}\right)$; Valor T: CTC e V\%: saturação por bases [(S/T $\left.)^{*} 100\right]$. 
número de anéis formados, com a natureza e concentração do íon metálico e com o pH.

\section{Classificação dos solos}

Os teores de matéria orgânica, quantificados pelo método da mufla, foram utilizados como padrão para a distinção do tipo de material (orgânico ou mineral). Esse método é mais adequado para solos com elevados teores de MO (Embrapa, 2006; Pereira et al., 2006), em detrimento aos métodos de oxidação via úmida (com uso de dicromato de potássio). Adicionalmente, a presença de pirita em alguns dos solos estudados pode levar a superestimativa dos teores de CO pelo método da via úmida (Souza Jr. et al., 2001b). Para o cálculo dos teores de $\mathrm{MO}$ a partir dos teores de $\mathrm{CO}$ foi utilizada a razão 1,724 (Embrapa, 1997) (Quadro 4).

Quadro 5. Teores de micronutrientes em Organossolos da região Nordeste do Brasil

\begin{tabular}{|c|c|c|c|c|}
\hline Horizonte & Mn & $\mathrm{Zn}$ & $\mathbf{C u}$ & $\mathrm{Fe}$ \\
\hline & & \\
\hline & & rfil CE1 & & \\
\hline Hdon 1 & 26,80 & 75,59 & 0,77 & 443,24 \\
\hline Hdon2 & 22,87 & 65,99 & 1,25 & 447,52 \\
\hline Hoj & 28,01 & 100,79 & 6,03 & $3.768,15$ \\
\hline $\mathrm{Cg}$ & 4,75 & 10,06 & 0,54 & 650,75 \\
\hline Cgn & 2,88 & 5,49 & 0,24 & 318,81 \\
\hline \multicolumn{5}{|c|}{ Perfil CE2 } \\
\hline Agp & 50,52 & 83,37 & 3,06 & 543,02 \\
\hline Hdo & 34,59 & 177,43 & 3,40 & 502,83 \\
\hline Ho & 83,33 & 244,00 & 5,87 & $1.213,64$ \\
\hline $\mathrm{Hdj}$ & 37,96 & 168,14 & 5,81 & $1.492,08$ \\
\hline Cgj & 1,75 & 4,42 & 0,00 & 201,37 \\
\hline \multicolumn{5}{|c|}{ Perfil RN1 } \\
\hline Hdp1 & 45,74 & 1,90 & 0,00 & 48,79 \\
\hline Hdp2 & 37,83 & 2,38 & 0,00 & 94,59 \\
\hline Hdo1 & 8,51 & 3,48 & 0,00 & 240,92 \\
\hline Hdo2 & 5,44 & 5,24 & 0,00 & 478,51 \\
\hline \multicolumn{5}{|c|}{ Perfil RN2 } \\
\hline Hdp & 77,89 & 11,06 & 0,00 & 25,85 \\
\hline Hdo & 12,49 & 3,64 & 0,00 & 8,34 \\
\hline Ho1 & 10,34 & 3,24 & 0,00 & 35,26 \\
\hline Ho 2 & 10,22 & 3,83 & 0,00 & 26,37 \\
\hline \multicolumn{5}{|c|}{ Perfil PB1 } \\
\hline $\mathrm{Hd} 1$ & 2,57 & 9,67 & 0,00 & 188,25 \\
\hline $\mathrm{Hd} 2$ & 1,12 & 3,65 & 0,61 & 46,08 \\
\hline $\mathrm{Cg} 1$ & 0,97 & 1,08 & 0,43 & 44,04 \\
\hline $\mathrm{Cg} 2$ & 0,17 & 0,52 & 0,27 & 41,12 \\
\hline \multicolumn{5}{|c|}{ Perfil PB2 } \\
\hline Hdp & 16,57 & 5,31 & 0,64 & 7,85 \\
\hline $\mathrm{Hd}$ & 29,14 & 8,38 & 0,40 & 19,15 \\
\hline Hdo1 & 15,99 & 2,97 & 0,21 & 9,17 \\
\hline Hdo2 & 22,38 & 8,97 & 0,25 & 0,75 \\
\hline
\end{tabular}

Todos os solos apresentaram teores de $\mathrm{CO}$ maiores de $80 \mathrm{~g} \mathrm{~kg}^{-1}$ de C e de MO maiores que 137,92 $\mathrm{g} \mathrm{kg}^{-1} \mathrm{e}$ espessura maior ou igual a $40 \mathrm{~cm}$; portanto, classificados com Organossolos no primeiro nível categórico (Quadro 6).

No segundo nível categórico, os Organossolos foram classificados com Háplicos, exceto o perfil CE1, que, por apresentar horizonte sulfúrico com espessura maior que $15 \mathrm{~cm}$, classificou-se como Tiomórfico. No horizonte Hdj do perfil CE2 também ocorre o processo de sulfidização, caracterizado pelo valor de $\mathrm{pH}$ menor que 3,5. No entanto, esse não atende ao critério de espessura para ser classificado como horizonte sulfúrico (Embrapa, 2006).

A classificação dos horizontes Hísticos no terceiro nível categórico, quanto ao grau de decomposição da $\mathrm{MO}$, foi feita com o emprego da relação dos teores de fibras esfregadas e o índice de pirofosfato (Figura 3), havendo forte relação entre essa classificação e os valores de classes obtidos pelo método de von Post realizado no campo (Quadro 3).

O perfil PB1 apresentou horizonte Hístico com material orgânico em avançado estádio de decomposição, classificado como Sáprico. Já no perfil $\mathrm{RN} 2$, foi observado predomínio de material orgânico menos decomposto, sendo classificado como Fíbrico. Os demais perfis (CE1, CE2, RN1 e PB2), com predomínio de material de grau de decomposição intermediário, foram classificados como Hêmicos.

No perfil CE1, os elevados teores de $\mathrm{Na}^{+}$em subsuperfície atribuíram ao perfil o caráter solódico, enquanto em CE2 e PB1, a presença de camada de material de constituição mineral (glei) dentro de 100 $\mathrm{cm}$ a partir da superfície identificou esses solos como térricos. Os demais perfis (RN1, RN2 e PB2) foram classificados como típicos.

\section{CONCLUSÕES}

1. O aumento da Ds foi reflexo da decomposição do material orgânico e redução dos teores de matéria orgânica, que resultaram no aumento dos valores de DMO, MM e, consequentemente, do RM, que indicou maior subsidência dos solos.

2. O volume residual (VR) apresentou correlação significativa com outros atributos físicos, incluindo o $\mathrm{RM}$, podendo ser usado em estudos sobre subsidência de Organossolos.

3. A capacidade de armazenamento de água variou em razão do aumento dos teores de matéria orgânica.

4. A classificação dos solos refletiu da influência do material de origem e do ambiente de várzeas, com a formação de solos Tiomórficos e Solódicos em área de maior influência marinha, e do efeito da drenagem conduzindo a classes distintas de Organossolos Fíbrico, 


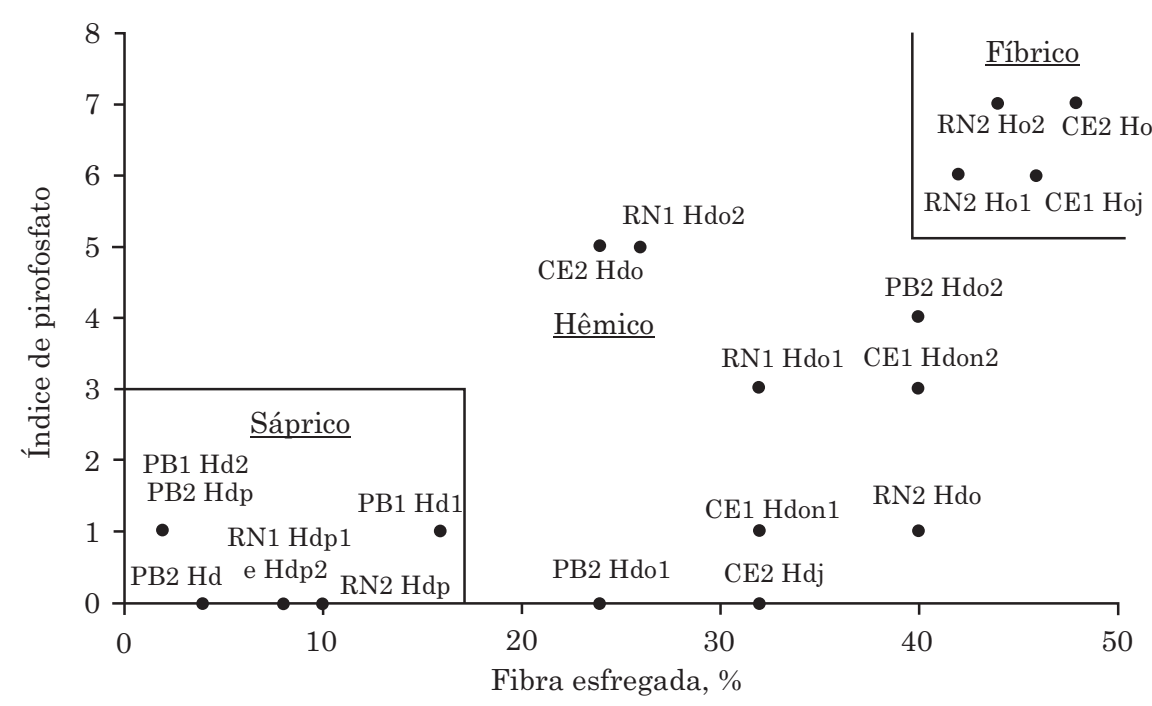

Figura 3. Grau de decomposição da matéria orgânica determinado em função da relação entre os valores de fibras esfregadas e o índice de pirofosfato. Sáprico: material orgânico em estádio avançado de decomposição; Hêmico: estádio intermediário; e Fíbrico: material orgânico pouco decomposto.

Quadro 6. Classificação dos Organossolos localizados nos Estados do Ceará, do Rio Grande do Norte e da Paraíba e suas principais características

\begin{tabular}{|c|c|c|}
\hline Perfil & Classificação $\operatorname{SiBCS}^{(1)}$ & Característica \\
\hline CE1 & Organossolo Tiomórfico Hêmico solódico & $\begin{array}{l}\text { Horizonte tiomórfico, predomínio de material orgânico hêmico, } \\
\text { caráter sódico e horizonte glei. }\end{array}$ \\
\hline CE2 & Organossolo Háplico Hêmico térrico & $\begin{array}{l}\text { Caráter tiomórfico, predomínio de material orgânico hêmico e } \\
\text { horizonte glei. }\end{array}$ \\
\hline RN1 & Organossolo Háplico Hêmico típico & Predomínio de material orgânico hêmico. \\
\hline $\mathrm{RN} 2$ & Organossolo Háplico Fíbrico típico & Predomínio de material orgânico fíbrico. \\
\hline PB1 & Organossolo Háplico Sáprico térrico & Predomínio de material orgânico sáprico e horizonte glei. \\
\hline PB2 & Organossolo Háplico Hêmico típico & Predomínio de material orgânico hêmico. \\
\hline
\end{tabular}

(1) SiBCS: Sistema Brasileiro de Classificação de Solos (Embrapa, 2006).

Hêmico e Sáprico, em razão da decomposição da matéria orgânica, além da variabilidade da espessura do conjunto de horizontes orgânicos.

\section{AGRADECIMENTOS}

Ao $\mathrm{CNPq}$, pela bolsa concedida; à Capes (PROCADNF 064/2010), pela bolsa concedida e pelo financiamento de parte da pesquisa; e aos Programas de Pós-Graduação em Agronomia-SNP da UFC e Agronomia- Ciência do Solo da UFRRJ.

\section{LITERATURA CITADA}

ANDRIESSE, J.P. Nature and management of tropical peat soils. Rome, FAO, 1988. (FAO Soils Bulletin, 59)
CHIMNER, R.A. \& EWEL, K.C. A tropical freshwater wetland: II. Production, decomposition, and peat formation. Wetlands Ecol. Manage., 13:671-684, 2005.

DRIESSEN, P.; DECKERS, J.; SPAARGAREN, O. \& NACHTERGAELE, F. Lecture notes on the major soils of the world. Rome, Food and Agriculture Organization of the United Nations, 2001. 334p. (FAO World Soil Resources Reports 94)

CAMPOS, J.R.R; SILVA, C.A. \& VIDAL-TORRADO, P. Mapping, organic matter mass and water volume of a peatland in Serra do Espinhaço Meridional. R. Bras. Ci. Solo, 36.723-732, 2012.

CAMPOS, J.R.R.; SILVA, A.C.; FERNANDES, J.S.C.; FERREIRA, M.M. \& SILVA, D.V. Water retention in a peatland with organic matter in different decomposition stages. R. Bras. Ci. Solo, 35:1217-1227, 2011a.

CAMPOS, J.R.R.; SILVA, A.C.; SILVA, E.B.; LUZ, R.C.S.; RIBEIRO, G.C. \& VIDAL-TORRADO, P. Método para análise de alumínio trocável em Organossolos. In: CONGRESSO BRASILEIRO DE CIÊNCIA DO SOLO, 33., 2011, Uberlândia. Anais... Uberlândia, 2011b. CD-ROM 
COUTO, E.G. \& RESENDE, M. Caracterização da matéria orgânica de alguns solos orgânicos e gleizados do Sudeste da Bahia. R. Bras. Ci. Solo, 9:185-191, 1985.

DAWSON, Q.; KECHAVARZI, C.; LEEDS-HARRISON, P.B. \& BURTON, R.G.O. Subsidence and degradation of agricultural peatlands in the Fenlands of Norfolk, UK. Geoderma, 154:181-187, 2010.

DINIZ FILHO, J.B.; MELO, J.G.; BARROSO, T.T. \& DUARTE, U. Potencialidades e consumo de águas subterrâneas no médio e baixo curso da bacia hidrográfica do rio CearáMirim/RN. In: JOINT WORLD CONGRESS ON GROUNDWATER, 1., 2000, Fortaleza. Anais... Groundwater, 2000. 20p.

EBELING, A.G.; ANJOS, L.H.C.; PEREZ, D.V.; PEREIRA, M.G. \& NOVOTNY, E.H. Atributos físicos e matéria orgânica de Organossolos Háplicos em distintos ambientes no Brasil. R. Bras. Ci. Solo, 37:763-774, 2013.

EMPRESA BRASILEIRA DE PESQUISA AGROPECUÁRIA EMBRAPA. Levantamento exploratório-reconhecimento de solos do Estado do Rio grande do Norte. Recife, SUDENE-DRN/Ministério da Agricultura, DNPEA-DPP, 1971. (Boletim Técnico 21; Série Pedologia 9)

EMPRESA BRASILEIRA DE PESQUISA AGROPECUÁRIA EMBRAPA. Levantamento exploratório-reconhecimento de solos do Estado da Paraíba. Rio de Janeiro, SUDENEDRN/Ministério da Agricultura, DNPEA-DPP, 1972. (Boletim Técnico 15; Série Pedologia 8)

EMPRESA BRASILEIRA DE PESQUISA AGROPECUÁRIA EMBRAPA. Manual de métodos de análise de solo. Rio de Janeiro, 1997. 212p.

EMPRESA BRASILEIRA DE PESQUISA AGROPECUÁRIA EMBRAPA. . Sistema Brasileiro de Classificação de Solos. 2. ed. Rio de Janeiro, Embrapa Solos, 2006. 306p.

FURRIER, M.; ARAÚJO, M.E. \& MENESES, L.F. Geomorfologia e tectônica da formação barreiras no Estado da Paraíba. Geol. USP, Ser. Cient., 6:61-70, 2006.

HERLIHY, M. \& McCARTHY, J. Association of soil-test phosphorus with phosphorus fractions and adsorption characteristics. Nutr. Cycl. Agroecol., 75:79-90, 2006.

KANG, B.T. \& OSINAME, O.A. Micronutrient problems in tropical Africa. Fert. Res., 7:131-150, 1985.

LAMIM, A.P.B.; JORDÃO, C.P.; PEREIRA, J.L. \& BELLATO, C.R. Caracterização química e física de turfa litorânea e avaliação da adsorção competitiva por cobre e zinco. Quím. Nova, 24:18-23, 2001.

LYNN, W.C.; McKINZE, W.E. \& GROSSMAN, R.B. Field laboratory test for characterization of Histosols. In: STELLY, M., ed. Histosols: their characteristics and use. Madison, Soil Science Society of America, 1974. p. 11-20. (SSSA Spacial Publication Series, 6)

LUCAS, R.E. Organic soils (Histosols): Formation, distribution, physical and chemical properties and management for crop production. East Lansing, Research Report, Farm. Science, Michigan State University, 1982. 80p. (Bulletin, 425)
NASCIMENTO, P.C.; LANI, J.L.; MENDONÇA, E.S.; ZOFFOLI, H.J.O. \& PEIXOTO, H.T.M. Teores e características da matéria orgânica de solos hidromórficos do Espírito Santo. R. Bras. Ci. Solo, 34:339-348, 2010.

NEVES, B.B.B.; ALBUQUERQUE, J.P.T.; COUTINHO, J.M.V. \& BEZERRA F.H.R. Novos dados geológicos e geofísicos para a caracterização geométrica e estratigráfica da Subbacia de Alhandra (Sudeste da Paraíba). R. Inst. Geoci./ USP, 9:63-87, 2009.

NICHOLS, D.S. \& BOELTER, D.H. Fiber size distribution, bulk density, and ash content of peats in Minnesota, Wisconsin, and Michigan. Soil Sci. Soc. Am. J., 48:13201328, 1984.

OLSEN, S.R.; COLE, C.V.; WATANABE, F.S. \& DEAN, L.A. Estimation of available phosphorus in soils extraction with sodium bicarbonate. Washington, USDA, 1954. 19p. (Circular, 939)

PEREIRA, M.G.; ANJOS, L.H.C. \& VALLADARES, G.S. Organossolos: Ocorrência, gênese, classificação, alterações pelo uso agrícola e manejo. In: TORRADO, P.V.; ALLEONI, L.R.F.; COOPER, M.; SILVA, A.P. \& CARDOSO, E.J., eds. Tópicos em ciência do solo. Viçosa, MG, Sociedade Brasileira de Ciência do Solo, 2005. v.4. p.233-276.

PEREIRA, M.G.; VALLADARES, G.S.; ANJOS, L.H.C.; BENITES, V.M.; ESPÍNDULA JR., A. \& EBELING, A.G. Organic carbon determination in Histosols and soil horizons with high organic matter content from Brazil (Note). Sci. Agric., 63:187-193, 2006.

PRADA-GAMERO, R.M.; VIDAL-TORRADO, P. \& FERREIRA, T.O. Mineralogia e físico-química dos solos de mangue do Rio Iriri no canal de Bertioga (Santos, SP). R. Bras. Ci. Solo, 28:233-243, 2004.

RIELEY, J.O.; WUST, R.A.J.; JAUHIAINEN, J.; PAGE, S.E.; WOSTEN, H.; HOOIJER, A.; SIEGERT, F.; LIMIM, S.H.; VASANDER , H. \& STAHLHUT, M. Tropical Peatlands: Carbon stores, carbon gas emissions and contribution to climate change processes. In: STRACK, M., ed. Peatlands and climate change. Calgary, Peat Society, 2008. p.44-70.

SANTOS, R.D.; LEMOS, R.C.; SANTOS, H.G.; KER, J.C. \& ANJOS, L.H.C. Manual de descrição e coleta de solo no campo. 5.ed. Viçosa, MG, Sociedade Brasileira de Ciência Solo, 2005. 100p.

SCHEER, M.B.; CURCIO, G.R. \& RODERJAN, C.V. Funcionalidades ambientais de solos altomontanos na Serra da Igreja, Paraná. R. Bras. Ci. Solo, 35:1113-1126, 2011.

SILVA, A.C.; HORAK, I.; MARTINEZ, A.; VIDAL-TORRADO, P.; RODRIGUES-RACEDO, J.; GRAZZIOTTI, P.H.; SILVA, E.B. \& PEREIRA, C.A. Turfeiras da Serrado Espinhaço Meridional - MG. I - Caracterização e classificação. R. Bras. Ci. Solo, 33: 1385-1398, 2009.

SOUZA Jr, V.S.; RIBEIRO, M.R. \& OLIVEIRA, L.B. Caracterização e classificação de solos tiomórficos da várzea do Rio Coruripe, no Estado de Alagoas. R. Bras. Ci. Solo, 25:977-986, 2001a. 
SOUZA Jr, V.S.; RIBEIRO, M.R. \& OLIVEIRA, L.B. Propriedades químicas e manejo de solos tiomórficos da várzea do Rio Coruripe, Estado de Alagoas. R. Bras. Ci. Solo, 25:811-822, 2001b.

VALLADARES, G.S.; PEREIRA, M.G.; ANJOS, L.H.C. \& EBELING, A.G. Caracterização de solos brasileiros contendo elevados teores de material orgânico. Magistra, 20:95-104, 2008a.
VALLADARES, G.S.; GOMES E.G.; MELLO, J.C.C.B.S.; PEREIRA, M.G.; ANJOS, L.H.C.; EBELING, A.G. \& BENITES, V.M. Análise dos componentes principais e métodos multicritério ordinais no estudo de Organossolos e solos afins. R. Bras. Ci. Solo, 32:285-296, 2008 b.

YONEBAYASHI, K.; OKAZAKI, M.; PECHAYAPISIT, J.; VIJARNSORN, P.; ZAHARI, A.B. \& KYUMA, K. Distribution of heavy metals among different bonding forms in tropical peat soils. Soil Sci. Plant Nutr., 40:425-434, 1994. 